\title{
The need for excellence centres in clinical imaging
}

\author{
Dr Bryan McIntosh, Associate Dean, division of service improvement and development at the \\ University of Bradford, and Christine Bishop, PhD researcher at the University of Bradford
}

\section{Introduction}

Within the UK there is a growing demand for clinical imaging and scanning. This demand is attributable to both a rapid advance in clinical (diagnostic) imaging technology over the last 30 years, and imaging being at the forefront of prediction, prevention, diagnosis and monitoring disease pathways.

There has been a year-on-year increase for clinical imaging examinations between 2007 and 2010, seeing annual rises of 2.9\%, 3.3\%, 5\% and 2.8\% (Royal College of Radiologists (RCR), 2012). Advances in pathways include the development of treatments and pathways for cancer screening, early diagnosis programmes, and new initiatives such as dementia imaging (Department of Health (DH), 2015).

There is an unfortunate variation however, in patient access for two reasons. The ability to secure appointments for basic imaging services are in high demand, and specialist equipment required to match new treatment pathways is available in certain hospitals only. Increased equity in patient access is required.

\section{Clinical partnerships}

While imaging technologies have advanced, education and training to support effective implementation of these technologies within clinical practice have not. Consequently, to increase capacity and enhance research, developments in clinical- academic-industry partnerships are becoming standard practice.

The University of Edinburgh has a long history of imaging excellence, combining skills of researchers, statisticians and clinical academics in disciplines such as brain, diagnostic, and orthopaedic imaging (University of Edinburgh, 2015). Imperial College London, King's College London and University College London became shareholders in a GlaxoSmithKline (GSK) dedicated research collaboration with surrounding hospitals-bringing together research heritage, skills of scientists and new technology as well as jobs for around 400 researchers and support staff.

This focus on creating a framework for collaboration across academia, pharmaceuticals and biotechnology, aims to transform biomedical research into direct healthcare and economic benefits (Kings College London, 2011). One can expect other hospitals and universities to do much of the same in coming years, assuring the constant development, dissemination and adoption of best practice standards, embedded in the design, delivery, and application of clinical imaging technologies.

\section{Unmet demand}

Despite these pockets of excellence, there remains an established unmet UK and global demand for more excellence centres capable of delivering a multi- skilled radiographer and sonographer workforce. Current approaches to clinical education and training are unable to address this demand.

The narrative of this reality, and potential for highly skilled technology employment opportunities, can be more frequently embedded within the UK, which will have a direct impact on the national economy. The layout of such centres would deliver:

- A workforce capable of exploiting current and future imaging technology to its highest potential through high quality, clinically validated, teaching and learning Capacity for advanced clinical imaging research, innovation, evaluation and translation into the clinical environment

- Patient-focused, service delivery embracing efficient models of high quality imaging provision

- Opportunities for national and international development driving growth in the technology, service and knowledge economies

- Creation of world leading technology and service standards for quality, effectiveness and efficiency in

- clinical imaging.

Research within clinical imaging would span a number of professional groups. These might include physicists, mathematicians, computer scientists, engineering disciplines and medical, healthcare professionals. A diverse range of 
professional groups working together is well known to be associated with higher levels of innovation in patient care (RCR, 2012). However, again there is the barrier of discrepancy between the benefits of combining multi-professional research innovations, standard equipment available in clinical practice and inconsistencies in dissemination. As a result, translation of research into practice is ad hoc and, due to a lack of unified practice standards a marked variation in image acquisition practices, education and service delivery models exist.

\section{Clinical demand}

A major role of excellence in clinical imaging will hopefully lead onto research translation and development of practice standards within key areas of demand. For example:

- Early diagnosis of dementia: The potential value of functional and molecular imaging in the early diagnosis of dementia is being increasingly recognised but further research is required to establish the cost-benefit models. There is also a gap in diagnosis and treatment pathways

- Cancer diagnostics, monitoring and treatment: A range of imaging modalities are used to identify, define and monitor cancer presence and spread. Imaging is central to the monitoring of disease progress and response to treatment. Anatomical imaging is increasingly being used

- to guide radiotherapy treatments, and reduce harm to normal tissues (National Audit Office (NAO), 2015b). We need to ensure all patients receive the right imaging at the right time regardless of service access route

- Bone health and obesity: Obesity and diet have a significant impact on the integrity of the skeletal structure, physical and mental health. We need to define best practice approaches

- for assessing early onset of bone degeneration and explore the links between diet, obesity and osteoporosis (NAO, 2015a). We also need to adopt imaging in the planning of surgical intervention

- $\quad$ and explore the value of $3 \mathrm{D}$ printing technologies in the production of personalised joint replacement implants

- Portable imaging for non- standard settings: Development of systems for non-hospital based use (Public Health England, 2015). For example, in field operations, at the site of accidents, in war zones and areas where access to imaging is limited by cost, environment and access to skilled users.

\section{Conclusion}

An increase in excellence centres for clinical imaging would impact on national and global standards, research translation, and present a new era in clinical-academic and industry partnership. Collaborations such as this offer a unique opportunity for all partners to benefit on an individual and collective basis enhancing the key technologies for delivery. For the Government, it offers an opportunity to produce unique facilities which will implement 7-day imaging directives and offer new models of service delivery and education that can be replicated both in the UK and globally.

\section{References}

Kings College London (2011) News:

$£ 76$ million research center to make the UK a global center of excellence for clinical imaging. Available at:

http://www.kcl.ac.uk/newsevents/ news/newsrecords/2011/o4Apr/

Jointventureinworld-classmedicalimaging. aspx (accessed 4 February 2016)

National Audit Office (2015a) Major Trauma Care in England, London www.nao.org.uk/trauma. Available at:

https://www.nao.org.uk/wp-content/

uploads/2010/02/0910213.pdf (accessed 5

February 2016)

National Audit Office (2015b) Progress in Improving Cancer Services and Outcomes in England. Available at: https://www. nao.org.uk/wp-content/uploads/2015/o1/ Progress-improving-cancer-services-and- outcomes-in-England.pdf (accessed 5

February 2016)

Public Health England (2015) The NHS Atlas of Variation in Healthcare. Reducing unwarranted variation to increase value and improve quality. Available at: http://www.rightcare.nhs.uk/atlas/RC_nhsAtlas3_HIGH_150915.pdf (accessed 5 February 2016)

Royal College of Radiologists (2012) Team Working in Clinical Imaging. Available at: https://www.rcr.ac.uk/sites/default/files/ publication/BFCR\%2812\%299_Team.pdf

(accessed February 4 2016)

University of Edinburgh (2015) Clinical imaging facilities. Available at: http:// www.ed.ac.uk/clinical-sciences/edinburghimaging/imaging-facilities/clinical-imaging- facilities (accessed 4 February 2016) 